\title{
Ethics of autism
}

\author{
Bert Gordijn · Henk ten Have
}

Published online: 12 June 2012

(C) Springer Science+Business Media B.V. 2012

Medical research on autism has advanced greatly in the 69 years since the condition was first described in publications by Leo Kanner (1943) and Hans Asperger (1944). Under the DSM-IV autism is now classified as a Pervasive Developmental Disorder (PDD) next to four others: Asperger Syndrome, Rett Syndrome, Childhood Disintegrative Disorder and Pervasive Developmental DisorderNot Otherwise Specified.

PDDs involve a diversity of impairments in social interaction, verbal and nonverbal communication, as well as various forms of restricted and repetitive patterns of behaviour. However, individuals with PDD may vary greatly in social and linguistics capabilities, intelligence and behavior. As yet there is no "cure" for any of the PDDs. Currently interesting research is being done in order to find out more about the genetic components associated with autism (see for example Sanders et al. 2011). Perhaps this will prove to be a promising avenue leading to new perspectives on diagnosis, prognosis and therapy.

The brief history of autism's relatively recent discovery and the development of different theoretical perspectives in trying to understand the phenomenon raise a plethora of philosophical questions about the epistemology and methodology of medicine, the nature of language and the mind, realism and social constructivism, the concepts of health and disease, and nature versus nurture, amongst others. In addition it has sparked ethical debate about the desirability of the quest for a cure, research ethics, the potential use of genetic testing, marginalization and stigmatization, personal identity, empathy, responsibility and moral status (see Barnbaum, 2008 for a good introduction).

B. Gordijn $(\varangle) \cdot$ H. ten Have Institute of Ethics, Dublin City University, Dublin, Ireland e-mail: bert.gordijn@dcu.ie
Against this backdrop the current issue of Medicine, Health Care and Philosophy features two papers about the ethics of autism. In "Should We Welcome a Cure for Autism?" R. Eric Barnes and Helen McCabe assess the assumptions underlying positions favouring or critical of a cure for autism. The approach of the authors is intentionally abstract. Barnes and McCabe are not focusing on the question of whether we should seek a cure, which would prompt further questions of feasibility and resource allocation; nor are they interested in assessing specific traits of potential cures for autism such as the time at which they would be offered, from the pre-natal stage to the fully grown adult. They evaluate the arguments for and against welcoming a cure, "were one to just fall into our laps", without going into too many real life specifics.

Pier Jaarsma, Petra Gelhaus and Stellan Welin are interested in the question of whether it is right to teach people with autism the social skill of lying. In their paper "Living the Categorical Imperative" they point out that whilst many neurotypical children who are not on the autistic spectrum have to be taught not to lie and cheat too much, deceptive behaviour is uncommon amongst children on the autism spectrum. What is more, the often uncompromising truthfulness of persons with autism may be an obstacle to developing smooth social relationship with others. Thus, from a care ethics perspective the authors argue that highfunctioning persons with autism should be taught the social skill of lying empathically in order to better respect the feelings and needs of other persons, unless such an education would undermine their own health and well-being.

\section{References}

Asperger, H. 1944. Die "Autistischen Psychopathen" im Kindesalter. Archiv für Psychiatrie und Nervenkrankheiten 117: 76-136. 
Barnbaum, D.R. 2008. The ethics of autism: Among them, but not of them. Bloomington: Indiana University Press.

Barnes, RE. and H. McCabe. Should we welcome a cure for autism? A survey of the arguments. Medicine, Health Care and Philosophy (this issue).

Jaarsma, P, P. Gelhaus, and S. Welin. Living the categorical imperative: Autistic perspectives on lying and truth telling- between kant and care ethics. Medicine, Health Care and Philosophy (this issue).

Kanner, L. 1943. Autistic disturbances of affective contact. Nervous Child 2: 217-250.

Sanders, S.J., et al. 2011. Multiple recurrent De Novo CNVs, including duplications of the 7q11.23 Williams syndrome region, are strongly associated with autism. Neuron 70(5): 863-885. 